\title{
Avaliação do conhecimento e atitudes de alunos do curso de Odontologia sobre o HIV/AIDS
}

\author{
Evaluation of the knowledge and attitudes of Dental students about HIV/AIDS \\ Evaluación de los conocimientos y actitudes de los estudiantes del curso de Odontología sobre \\ VIH/SIDA
}

Recebido: 13/04/2021 | Revisado: 20/04/2021 | Aceito: 26/04/2021 | Publicado: 10/05/2021

\author{
Washington Henrique Themoteo da Silva \\ ORCID: https://orcid.org/0000-0003-4684-309X \\ Universidade Federal de Uberlândia, Brasil \\ E-mail: wash.odonto@gmail.com \\ Paula Caetano Araújo \\ ORCID: https://orcid.org/0000-0001-6064-4906 \\ Universidade Federal de Uberlândia, Brasil \\ E-mail: pcaraujo@ufu.br
}

\begin{abstract}
Resumo
O objetivo da presente pesquisa consistiu na avaliação do conhecimento e atitudes dos estudantes da Faculdade de Odontologia da Universidade Federal de Uberlândia (FOUFU) sobre o HIV/AIDS. Este estudo transversal, utilizou um instrumento em forma de inquérito, a fim de coletar informações individuais, com graduandos do $7^{\circ}$ e $8^{\circ}$ períodos. Os resultados foram lançados no Microsoft Excel, sendo avaliados qualitativamente e quantitativamente. A amostra foi constituída por 61 discentes. Quanto a percepção sobre o HIV e experiências vivenciadas, 59\% dos participantes afirmaram ter prestado atendimento a pelo menos um paciente autodeclarado HIV positivo. Neste cenário ainda, $26 \%$ dos participantes pesquisados relataram ter sofrido algum tipo de acidente biológico. Cerca de $31 \%$ dos entrevistados afirmaram que um cirurgião-dentista soropositivo não deve continuar exercendo sua profissão sem informar seu status sorológico aos seus pacientes. Sobre o uso de óculos de proteção, $19 \%$ dos participantes não o citaram como equipamento de proteção individual nos atendimentos. Desta forma, a avaliação do conhecimento e atitudes dos discentes é adequado quanto ao desenvolvimento, transmissão do vírus e manifestações orais. Todavia, foi observado que faltou maior compreensão por parte da amostra ao que tange as medidas de biossegurança, manejo após acidente biológico, e responsabilidade civil e criminal.
\end{abstract}

Palavras-chave: Avaliação educacional; Estudantes de odontologia; HIV; Ensino.

\begin{abstract}
The aim of the present study consisted on the evaluation of knowledge and attitudes of students belonging to the Dental School of the Federal University of Uberlandia (UFU), about HIV/AIDS. This cross-sectional study used a questionnaire to collect individual information with undergraduate students, of the 7th and 8th semester. The results were analyzed by Microsoft Excel and were qualitatively and quantitatively evaluated. The sample consisted of 61 students. Regarding the perception of HIV and the experiences during the dental practice, 59\% of the participants stated that they had provided care to at least one self-declared HIV positive patient. In this scenario, $26 \%$ of the surveyed participants reported having suffered some type of biological accident. About $31 \%$ of respondents stated that a seropositive dental surgeon should not continue practicing his profession without informing his patients of his serological status. Regarding the use of goggles, $19 \%$ of the participants did not mention it as personal protective equipment when attending. Therefore, the knowledge evaluation and the student's attitudes are adequate regarding virus development, transmission and oral manifestations. However, it was observed the lack of understanding, by part of the sample, regarding biosafety measures, handling after a biological accident, and civil and criminal responsibility. Keywords: Educational measurement; Students, Dental; HIV; Teaching.
\end{abstract}

\section{Resumen}

El objetivo de esta investigación fue evaluar los conocimientos y actitudes de los estudiantes de VIH/SIDA de la Facultad de Odontología de la Universidad Federal de Uberlândia (FOUFU). Este estudio transversal utilizó un instrumento en forma de encuesta, con el fin de recolectar información individual, con estudiantes de pregrado del séptimo y octavo período. Los resultados fueron publicados en Microsoft Excel, siendo evaluados cualitativa y cuantitativamente. La muestra estuvo formada por 61 estudiantes. En cuanto a la percepción del VIH y las experiencias, el 59\% de los participantes manifestó haber prestado atención al menos a un paciente VIH positivo autodeclarado. En este escenario, el $26 \%$ de los encuestados reportaron haber sufrido algún tipo de accidente 
biológico. Aproximadamente el $31 \%$ de los encuestados afirmó que un cirujano dental seropositivo no debería seguir ejerciendo su profesión sin informar a sus pacientes de su estado serológico. En cuanto al uso de gafas, el 19\% de los participantes no lo mencionó como equipo de protección personal al asistir. Así, la evaluación de los conocimientos y actitudes de los estudiantes es adecuada en cuanto al desarrollo, transmisión del virus y manifestaciones orales. Sin embargo, se observó que la muestra carecía de un mayor conocimiento de las medidas de bioseguridad, manejo después de un accidente biológico y responsabilidad civil y penal.

Palabras clave: Evaluación educativa; Estudiantes de odontología; VIH; Ensenãnza.

\section{Introdução}

A Síndrome da Imunodeficiência Adquirida (AIDS) é uma doença retroviral, caracterizada pela ação do Vírus da Imunodeficiência Humana (HIV) (Sanabria, 2017). Este vírus ocasiona a destruição de linfócitos TCD4 e imunodepressão, aumentando assim a susceptibilidade do indivíduo contaminado às infecções oportunistas e neoplasias, que regularmente acarretam em desfecho letal (Roca et al., 2019; Santos et al., 2020; UNAIDS, 2020).

A AIDS não tem cura, sendo que suas principais formas de contágio são através de relações sexuais desprotegidas, aleitamento materno, transmissão vertical, transfusão de sangue não filtrada, uso de seringas por mais de uma pessoa, ou através de acidentes biológicos (Brasil, 2018). Os primeiros casos de AIDS foram confirmados no Haiti, Estados Unidos e África Central, nos anos de 1977 e 1978 (Brasil, 1978). No entanto, ela só foi determinada como síndrome em 1982 (Brasil, 1982; Silva et al., 2013).

Cerca de 76,1 milhões de pessoas foram contaminadas pelo HIV desde o início da epidemia até o ano de 2016, ocasionando 35 milhões de mortes relacionadas à doença (Brasil, 2017). Destaca-se ainda, a expressiva quantidade de indivíduos infectados pelo HIV em regiões subdesenvolvidas, como África Oriental e Austral (Maranhão \& Pereira, 2018). Em 2016, foi quantificado 790.000 novos casos, totalizando 19,4 milhões de portadores da doença nessa região (UNAIDS, 2017). Já na África Ocidental e Central, foi observado o maior percentual de mortes relacionadas à moléstia, atingindo, aproximadamente, 5\% das pessoas contaminadas, no ano de 2016 (UNAIDS, 2017). Segundo a Secretaria de Vigilância em Saúde, o Brasil confirmou nos últimos 37 anos, 882.810 casos de AIDS, sendo que nos últimos 5 anos, manteve um aumento médio de 40 mil novas infecções (UNAIDS, 2017). É importante ressaltar, que até o ano de 2016 foram registrados 316.088 óbitos devido a esta patologia (UNAIDS, 2017).

Apesar dos grandes avanços no tratamento antirretroviral, a doença ainda carrega consigo um grande estigma social (ABIA, 2016; Sanches et al. 2018). Estigma este, também observado na área da saúde (Wakayama, 2016; Lopes et al., 2019). A falta de conhecimento e o medo sobre o HIV, gera grande preconceito e recusa no tratamento de pessoas portadoras do vírus (Brasil, 2000; Honório et al., 2019). Embora o risco de contaminação durante o manejo clínico seja reduzido, a possibilidade de acidentes ocupacionais contendo material biológico gera grande estresse ao trabalhador (Sanches et al., 2018). Nesse contexto, a recusa no atendimento aos portadores do vírus, ainda é muito prevalente, ocasionando grande sofrimento e dificuldade de inserção destes indivíduos nos serviços de saúde (Brasil, 2000; Honório et al., 2019).

O cirurgião-dentista nas suas atividades clínicas enfrenta grandes desafios, como a dificuldade de acesso ao campo operatório e visão da área de trabalho (Nogueira et al., 2010). É relevante mencionar que este profissional faz uso de instrumentos perfurocortantes, bem como está sujeito a movimentos imprevisíveis do paciente, o predispondo a acidentes biológicos (Nogueira et al., 2010).

A inexperiência e insegurança dos estudantes de odontologia, são fatores agravantes para o aumento na prevalência de recusas no atendimento de indivíduos soropositivos. Destaca-se ainda, que estes sujeitos, muitas vezes, adotam atitudes que potencializam o risco de contaminação cruzada e exposição ocupacional (Wakayama, 2016; Honório et al., 2019).

Dentro deste contexto, durante o atendimento clínico de pacientes, os alunos realizam procedimentos invasivos, sem ter noção da condição sistêmica dos sujeitos atendidos (Olivial et al., 2008; Garbin et al., 2018). O paciente pode omitir a informação de 
forma consciente, devido ao constrangimento e medo de rejeição, ou até mesmo por próprio desconhecimento da doença (Olivial et al., 2008; Garbin et al., 2018).

Tais discentes acabam negligenciando os padrões de biossegurança, uma vez que não possuem informações que confirmem o quadro de virulência do enfermo (Lucena et al., 2016). É importante ressaltar o quão imprescindível é um atendimento realizado com cautela, respeitando todas as normas de biossegurança e utilizando todos os equipamentos de proteção individual, independente da condição de saúde do paciente (Lages et al., 2015; Lopes et al., 2019).

Os alunos do curso de odontologia como futuros profissionais da área de saúde, possuem o dever e responsabilidade de obter capacitação suficiente para realizar procedimentos respeitando os padrões de biossegurança, ofertando um serviço de maior qualidade e segurança, no atendimento de portadores do HIV (Garbin et al., 2018).

Nesse contexto, este estudo teve como objetivo a avaliação do conhecimento e atitudes dos estudantes da Faculdade de Odontologia da Universidade Federal de Uberlândia (FOUFU) acerca do tema HIV/AIDS.

\section{Metodologia}

O presente estudo observacional, analítico, de corte transversal, e análise quantitativa e qualitativa (Estrela, 2018), foi aprovado pelo Comitê de Ética em Pesquisa da Universidade Federal de Uberlândia (CAAE: 1990919.8.0000.5152). Este trabalho abordou o conhecimento e atitudes de alunos do curso de Odontologia da Universidade Federal de Uberlândia sobre o tema HIV/AIDS. O universo amostral desta pesquisa abrangeu um total de 61 alunos participantes. Sendo estes últimos, graduandos matriculados regularmente no $7^{\circ}$ e $8^{\circ}$ períodos. Os discentes participantes da pesquisa necessitavam ter concluído toda a fundamentação teórica a respeito do tema HIV/AIDS e deviam estar vivenciando a prática clínica odontológica nas dependências da Universidade.

A direção geral da Faculdade de Odontologia foi informada previamente, a respeito da metodologia empregada na pesquisa, bem como seus objetivos. Desta forma, foi enviada a direção, um requerimento para a aprovação da pesquisa a ser executada no âmbito acadêmico.

A pesquisa empregou um instrumento semiestruturado em forma de inquérito. Este instrumento foi aplicado aos graduandos do $7^{\circ} \mathrm{e} 8^{\circ}$ períodos, durante o momento de aula. O melhor momento para a aplicação do questionário foi acordado com antecedência com os docentes responsáveis pelo horário a ser utilizado. O pesquisador identificou-se e requisitou a participação dos alunos.

Concomitantemente com a autorização informal, o pesquisador informou que não seria admitido nenhum tipo de consulta para a realização do questionário. Este também ficou responsável por fiscalizar a realização do mesmo. Os Termos de Consentimento Livre Esclarecido foram entregues aos participantes e em seguida, foram assinados para que se iniciasse a entrega dos questionários.

Os graduandos participantes da pesquisa estavam cientes a respeito da temática abordada pelo questionário. É importante ressaltar, que o discente esteve livre para não participar do estudo e que a sua não participação não afetaria sua vida acadêmica. Os Termos de Consentimento Livre Esclarecido foram assinados por todos os discentes que aceitaram participar.

O presente trabalho empregou um questionário baseado nos instrumentos de pesquisas de Wakayama, 2016; Velos, 2007; Radicchi, 2001; Miranzi, 2003; Teixeira et al., 2016. Também contou com questões que foram incluídas devido às particularidades da Faculdade de Odontologia da Universidade Federal de Uberlândia (FOUFU). O questionário possuía 18 questões, abordando o tema HIV/AIDS ao que tange a percepção individual, conhecimento acerca das manifestações orais, responsabilidades civis, biossegurança, conduta em caso de acidentes biológicos, e desenvolvimento e transmissão da doença.

A coleta de dados foi realizada no $2^{\circ}$ semestre de 2019. Em relação à análise estatística descritiva, foi utilizado o programa Microsoft Excel 2016, abrangendo a somatória das prevalências e desenvolvimento de porcentagens. Ao que tange 
as questões abertas, foi utilizada a técnica de Bardin (2011), possibilitando a formação de categorias e consequentemente, a quantificação de respostas.

Por fim, foi enviado a direção da Universidade os resultados do instrumento aplicado aos discentes. Aos acadêmicos, foi enviado um informativo a respeito do assunto contido no questionário.

\section{Resultados}

A presente pesquisa de corte transversal compreendeu uma amostra total de 61 discentes do $7^{\circ}(39 \%)$ e $8^{\circ}(61 \%)$ períodos, sendo $59 \%$ do sexo feminino e $33 \%$ do sexo masculino ( $8 \%$ não responderam à questão). Os participantes apresentaram idade entre 19 e 31 anos, sendo a média 22,7 anos (11,4\% não informaram a idade). É importante destacar que houve uma perda de $23,7 \%$ da população estimada total.

\subsection{Percepção sobre o HIV e experiências vivenciadas}

Frente as questões a respeito da percepção dos discentes sobre o HIV e as experiências vivenciadas por eles, 59\% da amostra afirmou ter feito pelo menos um atendimento odontológico à pacientes portadores do HIV/AIDS. É importante ressaltar, que $26 \%$ dos participantes afirmaram ter vivenciado algum acidente de trabalho, sendo que $25 \%$ dessa população mencionou que as condutas realizadas após acidente foram: busca pelo centro de saúde, exame de sangue do paciente e exame de sangue do profissional. Destaca-se também, que 13\% dos participantes acidentados relataram não ter realizado nenhuma conduta para prevenção de contaminação.

Dentro deste contexto, quando foram indagados a respeito do nível de receio em prestar atendimento odontológico a pacientes HIV positivos, a maior parte dos estudantes (64\%) afirmaram possuir receio de nível médio e alto.

\subsection{Manifestações Orais do HIV}

Quanto à temática manifestações orais do HIV, foi possível observar que quando perguntados sobre a candidíase oral e a leucoplasia pilosa, grande parte da amostra (69\%) afirmou que estas patologias são marcadores de prognóstico em pacientes soropositivos (Gráfico 1).

Gráfico 1. Distribuição percentual do número de alunos que consideraram ou não a candidíase oral e a leucoplasia pilosa, marcadores de prognóstico em portadores de HIV/AIDS.

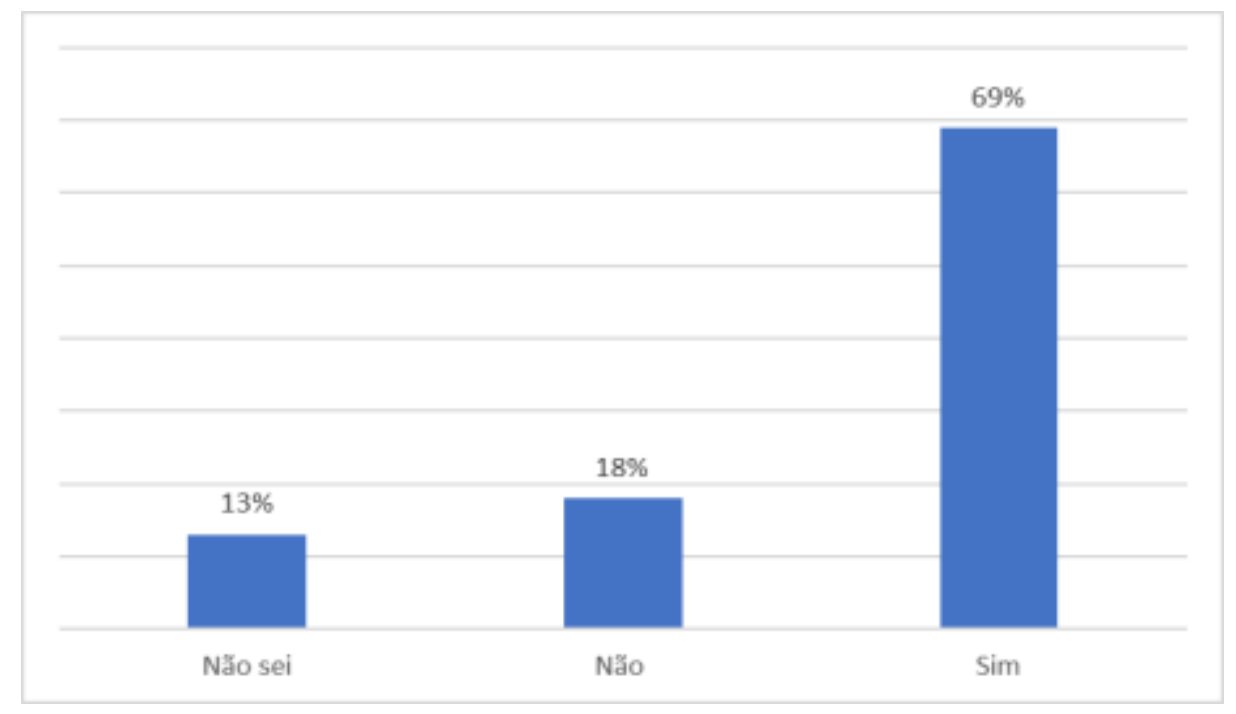

Fonte: Autores. 
O mesmo não pode ser observado quando os discentes foram questionados sobre a queilite angular como forma de manifestação da cândida em paciente soropositivos, sendo que apenas 34\% dos alunos acertaram esta questão. Em contrapartida, cerca de $89 \%$ dos graduandos participantes da pesquisa afirmaram corretamente que a doença cárie não pode ser considerada uma manifestação oral do HIV/AIDS.

\subsection{Responsabilidade civil e criminal}

Em relação às questões que abordaram o tema responsabilidade civil e criminal, foi possível identificar que $62 \%$ da amostra afirmou que o cirurgião-dentista detém o direito à solicitação do teste anti-HIV aos seus pacientes. Ressalta-se que 95\% dos participantes afirmaram que constitui crime punível, com detenção ou multa, ensejando processo civil e ético, o ato de realizar comentários a respeito do estado de saúde bucal ou sorológico de paciente, realizado pelo cirurgião-dentista, fora do ambiente de trabalho e sem o consentimento expresso desse paciente.

Ademais, foi verificado que 69\% da amostra considerou como direito de um profissional da saúde soropositivo, continuar a exercer sua profissão, sem ser obrigado a informar seu status sorológico aos pacientes.

\subsection{Biossegurança}

Considerando as perguntas sobre biossegurança, é importante ressaltar que $92 \%$ dos discentes afirmaram não existir diferenças clínicas no atendimento odontológico de pacientes portadores do HIV. Além disso, quando questionados sobre o uso de equipamentos de proteção individual (EPI), todos os graduandos pesquisados afirmaram utilizar esses dispositivos. Sendo que dentre os EPIs citados, os que tiveram maior prevalência foram: luva, máscara e gorro. Destaca-se ainda que 19\% dos discentes participantes não mencionaram o uso de óculos de proteção nos atendimentos.

Ressalta-se também, que $21 \%$ dos alunos participantes afirmaram que o reencape de agulhas utilizando as duas mãos, é uma medida biossegura (Gráfico 2).

Gráfico 2. Distribuição percentual do número de alunos que consideraram ou não o reencape de agulhas, utilizando as duas mãos, uma prática biossegura.

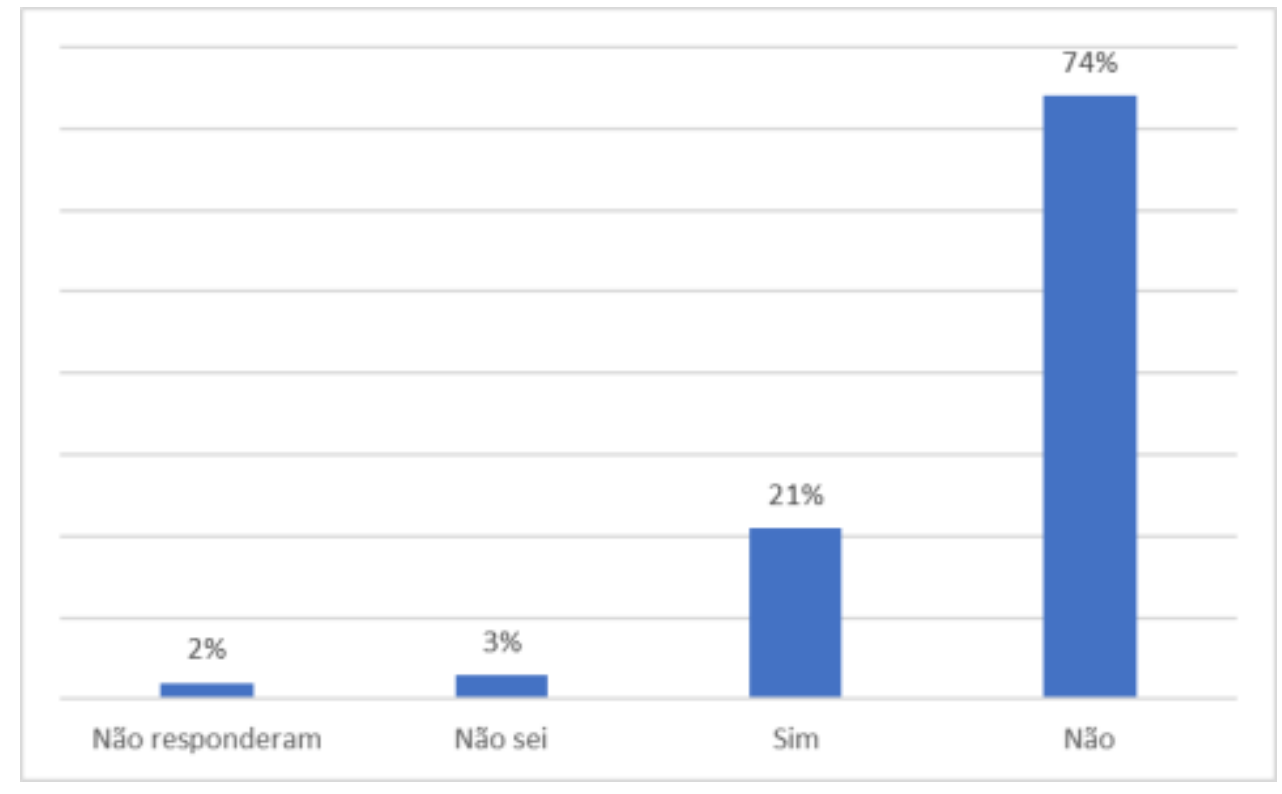

Fonte: Autores. 
Ainda dentro deste contexto, $75 \%$ da amostra considerou que a transmissão de infecções via procedimentos odontológicos é suficientemente prevenida, pelas medidas universais de controle de infecção.

\subsection{Acidentes biológicos}

Sobre os acidentes biológicos, $74 \%$ dos alunos entrevistados consideraram que o profissional de saúde que sofreu acidente biológico, deve fazer os testes pós-exposição, assim que possível. É importante ressaltar que $16 \%$ da amostra não soube responder sobre a existência do formulário de Comunicado de Acidente de Trabalho (CAT), sendo que 25\% afirmou que este formulário não existe no ambiente clínico em que atua (Gráfico 3).

Gráfico 3. Distribuição percentual do número de alunos que afirmaram ou não a existência de formulário de comunicação de acidente de trabalho, no ambiente clínico em que atuam.

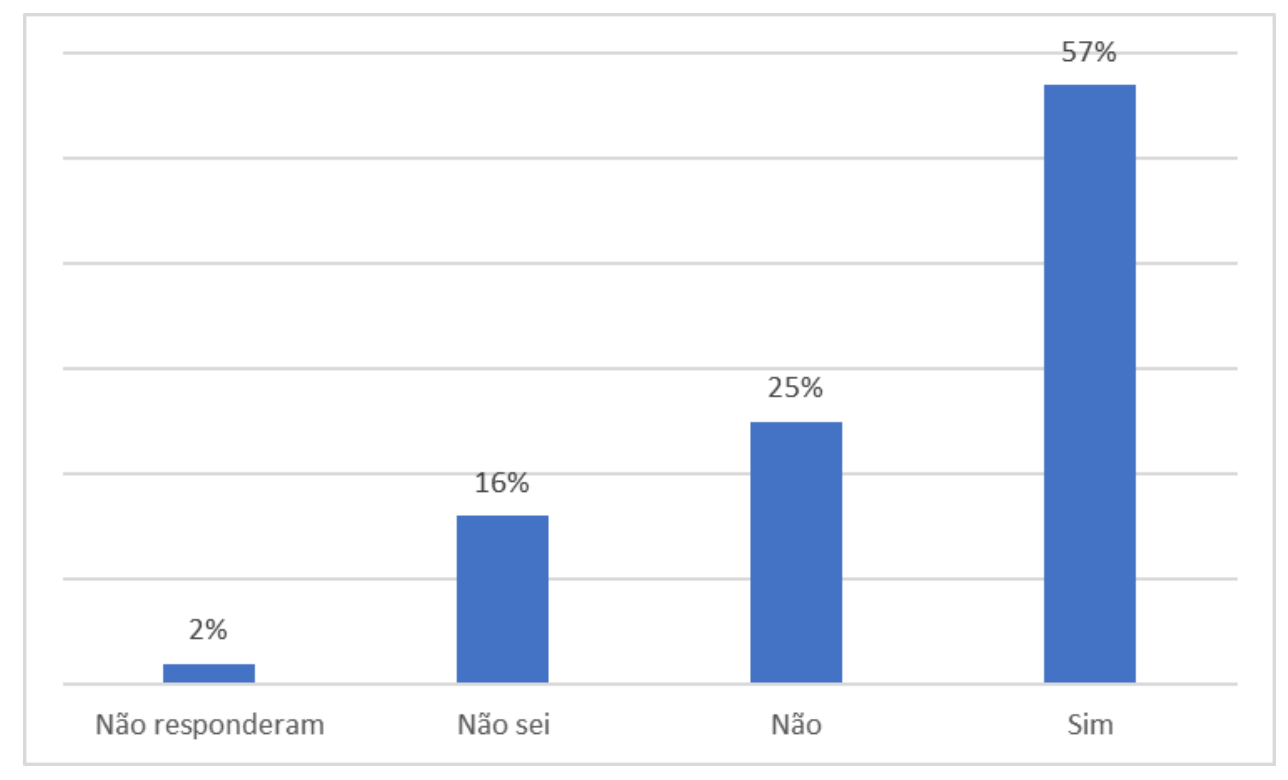

Fonte: Fonte: Autores.

A grande maioria dos pesquisados (98\%) relataram que pessoas contaminadas pelo vírus HIV não tem manifestação rápida de sinais e sintomas. Destaca-se ainda que $95 \%$ da amostra afirmou que a contaminação pelo vírus HIV não se dá através do contato com fluídos corporais do tipo saliva, lágrima, suor e urina. É válido ainda ressaltar que $95 \%$ dos participantes confirmaram que a infecção primária pelo HIV ocorre geralmente de 2 a 4 semanas após o contágio, e é caracterizada por sintomas do tipo febre, mal-estar, mialgia e cefaleia.

\section{Discussão}

Atualmente, existe uma tendência de estabilização da epidemia do HIV/AIDS no Brasil (Brasil, 2020). Estima-se que 886 mil pessoas estejam contaminadas pelo vírus (Brasil, 2020). É importante ressaltar que o conhecimento apropriado sobre a doença por parte dos recursos humanos em saúde é essencial, uma vez que preconceitos são desconstruídos e consequentemente os riscos de contaminação são minimizados (Brasil, 2020). Destaca-se assim, a relevância do ensino odontológico humanizado e generalista para formação de futuros cirurgiões-dentistas melhor preparados, para o cuidado em saúde desta população (Lucena et al., 2016). 
Nesse contexto o presente estudo avaliou o conhecimento e atitudes dos discentes da Faculdade de Odontologia da Universidade Federal de Uberlândia, sobre a temática HIV/AIDS. A amostra compreendeu alunos do $7^{\circ}$ e $8^{\circ}$ períodos ( $\mathrm{n}=61$ ). O presente estudo teve uma perda amostral de $23,7 \%$ dos sujeitos da amostra esperada ( $\mathrm{n}=80$ ).

Foi possível observar que a amostra foi composta por 59\% de participantes do sexo feminino e $33 \%$ do sexo masculino, compatível com outros estudos com proposta semelhantes a essa pesquisa (Wakayama, 2016; Miotto, 2012; Velos, 2007). Esse achado pode ser explicado devido ao processo de feminização da odontologia, transformação ocorrida a partir dos anos 90, que trouxe maior número de trabalhadores do sexo feminino para o setor (Silva et al., 2019). Destaca-se ainda que a profissão era exercida predominantemente por homens antes desse período (Silva et al., 2019).

Ainda em relação aos estudantes da área de saúde, estes recursos humanos em formação podem ser considerados grupos vulneráveis à acidentes ocupacionais. A falta de experiência e insegurança no manejo clínico são fatores importantes que sujeitam estes indivíduos a tais acidentes (Melo et al., 2020). É possível observar essa vulnerabilidade uma vez que, 26\% da amostra desse estudo afirmou ter vivenciado algum tipo de acidente de trabalho, sendo que 13\% afirmou não realizar nenhuma conduta frente a esse tipo de ocorrência.

Todos estes fatores influenciam diretamente no desenvolvimento de preconceitos no atendimento do paciente soropositivo, consequentemente aumentando o medo da realização do tratamento odontológico nesta população. No presente estudo, quando a amostra foi questionada quanto ao receio em atender pacientes soropositivos, a maior parcela dos estudantes (64\%) afirmou possuir receio médio e alto. O estudo de Wakayama em 2016, corrobora com este achado, sendo que em seu estudo foram observados $84 \%$ de estudantes com receio médio e alto.

Dos alunos participantes da presente pesquisa, cerca de 59\% afirmaram ter prestado atendimento a pelo menos um paciente autodeclarado HIV positivo, superando os dados encontrados nos estudos de Radicchi et al. (2001) e Velos (2007) com menos da metade da amostra declarando ter atendido pacientes portadores do vírus HIV.

Tendo em vista o aumento progressivo do número de pacientes atendidos por estudantes de odontologia ao longo do curso, aumenta-se também a sua exposição a possíveis contaminações, consequentemente se faz imprescindível a aplicação de práticas de biossegurança (Melo et al., 2020). Foi possível observar através da presente pesquisa que apesar de todos os alunos pesquisados afirmarem fazer uso de EPIs, $19 \%$ não citaram os óculos de proteção como um dos dispositivos utilizados em seus atendimentos. Essa informação é compatível com os estudos de Hermenegildo (2019) e Melo et al. (2020), que encontraram em suas amostras uma negligencia no uso de óculos de proteção de 13,5\% e 32\%, respectivamente.

Considerando a melhor formação possível dos recursos humanos em saúde, a atenção com suas obrigatoriedades éticas e morais, se fazem indispensáveis (Radicchi, 2001). É importante citar que conforme instituído na Lei 2.848 de 07 de dezembro de 1940, do código penal brasileiro, o artigo 154 demonstra que constitui crime punível, com detenção de três meses a um ano ou multa, a revelação de segredos obtidos em função da profissão (Brasil, 1940). Destaca-se também que no artigo 325 do mesmo documento, consta que a revelação ou facilitação da revelação de qualquer fato que deva permanecer em segredo, que se tenha ciência por meio de cargo profissional, pode gerar pena de reclusão de um a quatro anos, e multa (Brasil, 1940). Além do mais, a quebra de sigilo profissional sem justa causa, deve ser considerada infração ética de acordo com o capítulo IV, artigo 14 do Código de Ética Odontológica, aprovado pela resolução Conselho Federal de Odontologia - 118/2012 (CFO, 2012).

Diante do acima exposto, $95 \%$ da amostra entrevistada neste estudo afirmou que qualquer comentário sobre o estado de saúde bucal ou status sorológico de um paciente, realizado pelo cirurgião-dentista fora da relação profissional, constitui crime punível, com detenção ou multa, ensejando processo civil e ético. O trabalho realizado por Radicchi (2001), corrobora com os achados do presente estudo, uma vez que $75 \%$ de sua amostra fez a mesma afirmação. 
No tocante à transmissão do HIV, o vírus se encontra presente em secreções como sangue, esperma, secreção vaginal e leite materno, por consequência a sua transmissão se dá através do uso compartilhado de seringas, transfusão de sangue contaminado, acidentes com perfurocortantes não esterilizados, relações sexuais desprotegidas, transmissão vertical e aleitamento materno (ABIA, 2016; Brasil, 2020). Por conseguinte, 95\% dos participantes dessa pesquisa afirmaram que o contato com fluidos corporais como saliva, lágrima, suor e urina não possuem potencial de transmissão do HIV, mostrando maior porcentagem de acertos quando comparada ao estudo de Teixeira et al. (2016), que apresentou 80\% de afirmações corretas.

Posteriormente a infecção do HIV, o vírus causador da AIDS, o desenvolvimento da patologia pode ocorrer em três etapas (Brasil, 2020). A primeira fase denominada síndrome retroviral aguda também conhecida como infecção HIV aguda é responsável pelo período de incubação do vírus, possui duração de 2 a 4 semanas após o contágio, apresentando os primeiros sinais e sintomas da doença, sendo estes similares aos de uma gripe comum (Brasil, 2020). Dos discentes pesquisados, 95\% souberam responder sobre a infecção aguda do HIV, sendo que $98 \%$ afirmaram corretamente que uma pessoa recém-infectada pelo vírus, não apresenta rapidamente os sinais e sintomas.

$\mathrm{O}$ organismo humano requer de 30 a 60 dias após o contágio, para que sejam produzidos anticorpos anti-HIV, qualquer testagem antes desse processo terá possivelmente resultado não reagente, este intervalo é chamado de janela imunológica (UNAIDS, 2020). A fase seguinte é caracterizada por ser assintomática, é o estágio de latência clínica, sendo conhecida como infecção HIV crônica ou infecção HIV assintomática (Brasil, 2020; UNAIDS, 2020). O UNAIDS (Programa Conjunto das Nações Unidas sobre HIV/AIDS) afirma que o vírus ainda continua ativo, porém com redução nos níveis de replicação (Brasil, 2020; UNAIDS, 2020).

Já na terceira fase ocorre uma mudança do quadro sintomatológico, sendo que o sistema imune já se encontra tão deficiente e a contagem de linfócitos normais tão diminuída, que o indivíduo se mantém vulnerável às infecções oportunistas e neoplasias, evoluindo para a síndrome da imunodeficiência humana adquirida (Brasil, 2013; Brasil, 2020; UNAIDS, 2020).

Dentro deste contexto, os cirurgiões-dentistas assim como a equipe de saúde bucal estão mais susceptíveis a patologia devido ao risco de acidentes com perfurocortantes, tanto no atendimento, quanto no manuseio de instrumentais odontológicos não esterilizados (Trezena et al., 2020). Tornando fundamental o conhecimento do profissional da saúde quanto ao protocolo de exposição a materiais biológicos, com o intuito de facilitar a conduta inicial após o acidente ocupacional (Brasil, 2006).

O protocolo de exposição a materiais biológicos imposto pelo Ministério da Saúde, em 2006, define que a conduta imediata após acidente com perfurocortante consiste na interrupção do procedimento e realização da lavagem da superfície cutânea ou percutânea acidentada, com água e sabão. Em caso de mucosa, utilizar apenas água ou solução salina, descriminando o uso de soluções irritantes e contraindicando ainda, procedimentos que aumentem ou provoquem irritações à área exposta (Brasil, 2006).

Em seguida, deverá ser realizado o Comunicado de Acidente de Trabalho (CAT), sendo este de responsabilidade da empresa empregadora, bem como o registro no formulário do Sistema de Informação de Agravos de Notificação (SINAN) (Brasil, 2013; Brasil, 2018a). A notificação deste último é realizada pelo profissional que acolhe o paciente acidentado (Brasil, 2013; Brasil, 2018a).

É importante salientar que $41 \%$ dos estudantes universitários pesquisados nesse estudo afirmaram desconhecer que o formulário CAT está disponível no ambiente clínico. Destaca-se ainda que um estudo realizado em 2001 por Radicchi encontrou que 66,5\% dos entrevistados não dispunham do formulário CAT no local de atuação.

O protocolo de exposição a materiais biológicos informa ainda que a indicação da quimioprofilaxia antirretroviral dependerá de fatores como: tipo de exposição, tecidos e materiais envolvidos, tempo de exposição e status sorológicos tanto da fonte quanto do acidentado (Brasil, 2018b). 
A profilaxia após exposição (PPE) não está indicada nos seguintes casos: acidentes com 72 horas ou mais da ocorrência, vítimas infectadas previamente ao acidente atual, acidentes sem risco de transmissão efetivo (fonte comprovadamente soronegativa para o HIV, exposição a fluído sem potencial de transmissão, e exposição sem existência real de infecção) (Brasil, 2018b).

Após a indicação da PPE, o acidentado deve utilizar os medicamentos durante 28 dias subsequentes à exposição, sendo que ao completar uma semana é realizado um exame de verificação quanto à adesão e efeitos adversos (Brasil, 2008). Os principais sistemas medicamentosos são: esquema básico composto por AZT (zidovudina) associado à 3TC (lamivudina) e esquema expandido constituído por AZT, 3TC e TDF (tenofir) (Brasil, 2018b).

O acompanhamento sorológico de rotina é realizado independente do uso da PPE, através do teste anti-HIV no momento da exposição, após seis semanas, 3 meses e 6 meses após o acidente (Brasil, 2018b). Dentro desse contexto, cerca de $74 \%$ da amostra soube responder corretamente os prazos das testagens, porcentagem superior à encontrada por Radicchi em 2001, que demonstrou que $60 \%$ dos entrevistados possuíam conhecimentos sobre tal procedimento. Todavia, é importante destacar que a infecção pelo HIV após exposição ocupacional, via percutânea, no contato direto com sangue, é baixa $(0,3 \%)$ (Brasil, 2018b). Por conseguinte, é de extrema importância a realização de todo o protocolo de exposição à materiais biológicos, assim como a realização das testagens anti-HIV, anti-HCV (hepatite C), e HBsAg, Anti-HBc (hepatite B) (Brasil, 2018b).

\subsection{Limitações encontradas}

O projeto pedagógico da Faculdade de Odontologia da Universidade Federal de Uberlândia está em constante aprimoramento, disponibilizando a melhor formação acadêmica possível aos futuros cirurgiões-dentistas, regularmente vinculados a esta instituição. Contudo, é importante salientar que os resultados obtidos nessa pesquisa compreendem particularidades exclusivas da FOUFU, não podendo ser aplicados de forma genérica à outras instituições odontológicas existentes.

O estudo teve apenas dois momentos de aplicação do instrumento de pesquisa, sendo que não foi considerada as experiências dos graduandos não presentes no momento da coleta de dados. Desta forma, a perda amostral pode ser considerada um limitador no alcance das características dos períodos avaliados (n=19). Também é importante levar em consideração que todas as questões dependem da interpretação individual de cada participante, quando há uma má interpretação ou falta de atenção ao responder o questionário, prejuízos e vieses à pesquisa podem surgir.

\section{Conclusão}

Por conseguinte, foi possível observar que os graduandos da Faculdade de Odontologia da Universidade Federal de Uberlândia possuem conhecimento adequado ao que tange o desenvolvimento, a transmissão e as manifestações orais do HIV/AIDS. No entanto foi observado que faltou maior compreensão por parte da amostra acerca das medidas de biossegurança, manejo após acidentes biológicos, e responsabilidade civil e criminal.

Ademais, preconiza-se como implicações para novos estudos a avaliação dos planos de ensino das disciplinas que oferecem o conteúdo avaliado, a fim de indicar de forma mais pontual as dificuldades encontradas. Novos estudos também devem avaliar os discentes em outros períodos da faculdade a fim de melhor capturar deficiências do projeto pedagógico.

Sugere-se ainda a realização de futuros estudos comparando diferentes Faculdades de Odontologia, a fim de analisar o projeto pedagógico que se faz mais completo e eficiente, na visão do discente. 
Por fim, o presente estudo sugere à FOUFU, maior orientação aos discentes quanto a disponibilização do Formulário de Comunicado de Acidente de Trabalho, bem como, a instrução e treinamento quanto ao passo a passo do protocolo de acidentes biológicos.

\section{Agradecimentos}

Ao PIBIC CNPq/UFU Edital nº 2/2019, pelo apoio financeiro através da bolsa de iniciação científica.

\section{Referências}

Associação Brasileira Interdisciplinar De Aids (ABIA). (2016). ABIA esclarece dúvidas a transmissão do HIV. Observatório Nacional de Política de AIDS.

Bardin, L. (2011). Análise de conteúdo. Edições 70.

Brasil. (1940). Decreto-Lei 2.848. Código Penal. Diário Oficial da União.

Brasil. (1978). História da Aids - 1977 e 1978. Ministério da Saúde. Departamento de doenças crônicas e infecções sexualmente transmissíveis.

Brasil. (1982). História da Aids - 1982. Ministério da Saúde. Departamento de doenças crônicas e infecções sexualmente transmissíveis.

Brasil. (2000). Seminário de Cooperação Brasil / França: profissionais de saúde frente ao manejo da infecção pelo HIV: aspectos psicossociais e técnicos. Ministério da Saúde. Secretária de Vigilância da Saúde.

Brasil. (2006). Exposição a materiais biológicos. Ministério da Saúde, Secretaria de Atenção à Saúde, Departamento de Ações Programáticas Estratégicas. Ministério da Saúde. Secretaria de Atenção à Saúde. Departamento de Ações Programáticas Estratégicas.

Brasil. (2008). Recomendações para terapia antirretroviral em adultos infectados pelo HIV: manual de bolso. Ministério da Saúde. Secretária de Vigilância da Saúde. Programa Nacional de DST e Aids.

Brasil. (2013). Perguntas frequentes. Sistema de Informação de Agravo de Notificação.

Brasil. (2017). Boletim epidemiológico HIV AIDS. Brasília. Ministério da Saúde. Secretária de Vigilância da Saúde.

Brasil (2018a). Comunicação de Acidente de Trabalho - CAT. Ministério da Economia. Instituto Nacional do Seguro Social.

Brasil. (2018b). Protocolo clínico e diretrizes terapêuticas para profilaxia pós exposição (PEP) de risco à infecção pelo HIV, IST e hepatites virais. Ministério da Saúde. Secretária de Vigilância da Saúde. Departamento de doenças crônicas e infecções sexualmente transmissíveis.

Brasil. (2020). Aids / HIV: o que é, causas, sintomas, diagnóstico, tratamento e prevenção. Ministério da Saúde.

Conselho Federal de Odontologia (CFO). (2012). Resolução CFO n ${ }^{\circ} 118$, de 11 de maio de 2012. Revoga o Código de Ética Odontológica aprovado pela Resolução CFO 42/2003 e aprova outro em substituição. Diário Oficial da União. Brasília; Seção 1, nº 114. p. 118. Conselho Federal de Odontologia.

Estrela, C. (2018). Metodologia Científica: Ciência, Ensino, Pesquisa. Editora Artes Médicas.

Garbin, C. A. S., Wakayama, B., Saliba, T. A., Saliba, O. \& Garbin, A. J. I. (2018). Discriminación y prejuicio. La influencia del VIH/SIDA y la Hepatitis B en la actitud de los académicos en odontología. Rev. Cienc. Salud, 16(2) 279-93.

Hermenegildo, N. J. (2019). Risco ocupacional em estudantes da área da saúde acerca do HIV/AIDS: uma revisão integrativa da literatura. Monografia (Graduação em Biomedicina) - Universidade Federal do Rio Grande do Norte, Natal.

Honório, E. F., Sganzerla, J. T., Mayer, S. N., Oliveira, M. C., Hernandez, P. A. G \& Miguens Jr, S. A. Q. (2019). Conhecimento e disposição de cirurgiõesdentistas no atendimento de portadores de HIV/AIDS no Sistema Único de Saúde de dois municípios do Sul do Brasil. Stomatos, 25(49).

Lages, S. M. R., Santos, A.F., Junior, F. F. S. \& Costa, J. G. (2015). Formação em odontologia: O papel das instituições de ensino na prevenção do acidente com exposição a material biológico. Cienc. Trab. 17(54), 182-7

Lopes, A. L., Rodrigues, L. G., Zina, L. G., Palmier, A. C., Vargas-Ferreira, F., Abreu, M. H. N. G. \& Vasconcelos, M. (2019). Biossegurança em Odontologia: conduta dos estudantes antes e após uma ação educativa. Revista da Abeno. 19 (2), 43-53.

Lucena, N. T., Petruzzi, M., Cherubini, K., Salum, F. \& de Figueiredo, M. (2016). Conhecimento, atitudes e práticas dos estudantes de Odontologia com relação a pacientes HIV positivos. Revista da Faculdade de Odontologia, Passo Fundo. 21(3), 388-94.

Maranhão, T. A. \& Pereira, M. L. D. (2018). Determinação social do HIV/aids: revisão integrativa. Revista baiana de enfermagem.

Melo, T. R. N. B., Costa, P. S., Oliveira, V. S., Diniz, M. A. G. \& Oliveira J. A. G. (2020). Avaliação do controle das medidas de biossegurança adotadas por acadêmicos de Odontologia. Revista Eletrônica Acervo Científico. 8, 2112.

Miotto, M. H. M. B. \& Rocha, R. M. (2012). Acidente ocupacional por material perfurocortante entre acadêmicos de Odontologia. Revista Brasileira em Promoção da Saúde. 25, 97-102. 
Research, Society and Development, v. 10, n. 5, e38510515019, 2021

(CC BY 4.0) | ISSN 2525-3409 | DOI: http://dx.doi.org/10.33448/rsd-v10i5.15019

Miranzi, M. A. S. (2003) Conhecimentos, atitudes e práticas frente a exposição ocupacional ao HIV entre estudantes, docentes e funcionários do curso de odontologia da Universidade de Uberaba. Tese (Doutorado) - Universidade Estadual de Campinas, Campinas.

Nogueira, A. S., Bastos, L. F. \& Costa, I. C. C. (2010). Riscos Ocupacionais em Odontologia: Revisão da Literatura. UNOPAR Científica, Ciências Biológicas e da Saúde. 12, 11-20.

Olivial, A. R. B., Charone, S. \& Groisman, S. (2018). A importância do exame odontológico periódico ocupacional: uma proposta de prontuário odontológico. Revista de Odontologia da Universidade Cidade de São Paulo, 20, 37-45.

Programa Conjunto das Nações Unidas sobre HIV/AIDS (UNAIDS) (2017). UNAIDS Dados 2017. < https://unaids.org.br/wpcontent/uploads/2015/06/20170720_DaDOS_unaids_Brasil.pdf>

Programa Conjunto das Nações Unidas sobre HIV/AIDS (UNAIDS) (2020). Informações básicas. <https://unaids.org.br/informacoes-basicas/>

Radicchi, R. (2001). Responsabilidade civil e criminal do atendimento odontológico ao paciente HIV soropositivo. Dissertação (Mestrado) - Universidade Estadual de Campinas, Piracicaba.

Roca, P., Landau, D. C., Mainardi, C., Kurpis, M. \& Lascano, A. R. (2019). Sarcoma de Kaposi en pacientes VIH: a propósito de dos casos. Rev. argent. dermatol. 100(2), 101-10.

Sanabria, G. V. (2017). Ciência, justiça e antropologia no debate sul-africano da AIDS: produção de sensibilidades e regulação moral entre especialista. Sexualidad, Salud y Sociedad, 26, 191-212.

Sanches, R. S., Souza, A. R. \& Lima, R. S. (2018). Fatores relacionados ao desenvolvimento de estresse e burnout entre profissionais de enfermagem que atuam na assistência a pessoas vivendo com HIV/aids. Revista Fundamental Care Online. 10, $276-82$.

Santos, J. L., Coser, J., Hammes, T. P., Mugnol, T., Garlet, A. M. \& Moreira, P. R. (2020). Comorbidades em Idosos Vivendo com HIV/Aids, 2020. Revista Saúde e Desenvolvimento Humano. 8, 1 .

Silva, M. F. R., Ribeiro, J. A. A., Cavalcante, G. M. S., Germano, S. C. F. \& Paredes, S. E. (2019). Perfil sociodemográfico e interesses profissionais de graduandos de Odontologia do Centro Universitário de Patos, 2019. Revista da Abeno. 19(4), 34-45.

Silva, M. M., Vasconcelos, A. L. R. \& Ribeiro, A. K. N. P. (2013). Caracterização epidemiológica dos casos de Aids em pessoas com 60 anos ou mais. Cadernos de Saúde Pública. 29(10), 2131-35.

Teixeira, L. O., Figueiredo, V. L. M. \& Mendonza-Sassi, R. A. (2016). Etapa Inicial da adaptação transcultural para o português do Brasil do HIV Knowledge Questionnaire (HIV-K-Q). Medicina (Ribeirão Preto). 49(4), 303-20.

Trezena, S., Farias, L. P. M., Barbosa, G. F. A., Costa, S. M., Barbosa, J. E. S. \& Coelho, P. M. Q. (2020). Práticas em biossegurança frente aos acidentes ocupacionais entre profissionais da odontologia. Arquivos em Odontologia, 56.

Velos, G. S. M. (2007). HIV/AIDS: conhecimento, atitudes e comportamento de cirurgiões-dentistas no estado de Mato Grosso. Dissertação (Mestrado) Universidade Estadual de Campinas, Piracicaba.

Wakayama, B. (2016). Hepatite B e HIV/AIDS: a representação social das doenças e a análise da imunização contra o vírus da hepatite B entre os alunos de odontologia. Dissertação (Mestrado) - Universidade Estadual Paulista “Júlio de Mesquita Filho”, Araçatuba. 